\title{
Article
}

\section{Developing a self-report measure to assess disclosure strategies in adult male prisoners and its association with personality}

Ferguson, Kerry, Ireland, Carol Ann and Ireland, Jane Louise Available at http://clok.uclan.ac.uk/8305/

Ferguson, Kerry, Ireland, Carol Ann ORCID: 0000-0001-7310-2903 and Ireland, Jane Louise ORCID: 0000-0002-5117-5930 (2013) Developing a self-report measure to assess disclosure strategies in adult male prisoners and its association with personality. Journal of Forensic Practice, 15 (2). pp. 97-108. ISSN 2050-8794

It is advisable to refer to the publisher's version if you intend to cite from the work. http://dx.doi.org/10.1108/14636641311322287

For more information about UCLan's research in this area go to http://www.uclan.ac.uk/researchgroups/ and search for <name of research Group>.

For information about Research generally at UCLan please go to http://www.uclan.ac.uk/research/

All outputs in CLoK are protected by Intellectual Property Rights law, including Copyright law. Copyright, IPR and Moral Rights for the works on this site are retained by the individual authors and/or other copyright owners. Terms and conditions for use of this material are defined in the policies page. 


\section{Developing a self-report measure to assess disclosure strategies in adult male prisoners and its association with personality}

Kerry Ferguson ${ }^{1 *}$, Dr. Carol A. Ireland ${ }^{2}$, and Prof. Jane L. Ireland ${ }^{3}$

${ }^{1} \mathrm{HM}$ Prison Service

${ }^{2}$ University of Central Lancashire

${ }^{3}$ University of Central Lancashire

Word count (inc. figures/tables): 5787

*Requests for reprints should be addressed to Kerry Ferguson at Kerry.Ferguson@hmps.gsi.gov.uk 
Purpose: The current study reports on the development of a self-report measure of disclosure strategies in adult male prisoners (violent and acquisitive offences) and its association with personality and self-esteem.

Design: The study employed an adapted version of the Delphi technique to develop initial items for inclusion in the new disclosure measure (Disclosure Management Questionnaire: DMQ). This element of the study utilised an 'expert sample' of Forensic Psychologists. Ninety four prisoners then completed the developed measure. Factor analysis was utilised to explore the structure of the measure, which subsequently allowed associations between disclosure strategies, personality and self-esteem to be identified.

Findings: Analysis revealed a measure of disclosure (the DMQ) comprising of four subscales; Exploratory Engagement, Placatory/Evasive Engagement, Passive Resistance and Active Resistance. Significant correlations were identified between the personality trait Neuroticism and higher levels of Placatory/ Evasive Engagement and Active Resistance of forensic clients during the disclosure process. Self-esteem was also found to correlate with disclosure, in that high trait self-esteem was found to be associated with higher exploratory engagement, whereas low trait self-esteem was associated with higher levels of active resistance of the disclosure process.

Value: Developing an understanding of the nature and function of disclosure and how these relate to individual factors such as personality (including trait self-esteem) provides valuable knowledge and alternative ways of supporting forensic clients in discussing difficult issues related to their offending.

Key Words: Disclosure, Personality, Self-Esteem, Forensic Clients 
Willingness to disclose information about one's offending behaviour is argued to be a critical factor in the change process of forensic clients (Frost, Ware and Douglas, 2009). The term 'disclosure' refers to the process by which a person reveals information about themselves, including their thoughts, feelings and experiences (Dindia, Fitzpatrick and Kenny, 1997). Although this concept has been widely researched in the field of social psychology, there is limited research into the disclosure of offenders, particularly when discussing topics that may be uncomfortable, such as offending behaviour. According to Frost, Daniels, and Hudson (2006) the exploration of strategies that individuals adopt during disclosure may provide practitioners with understanding about client engagement and the function this serves, therefore potentially increasing the effectiveness of interventions aimed at reducing reoffending.

Frost et al. (2006) used a sample of 16 sexual offenders engaged in treatment in New Zealand to explore disclosure strategies. Their study suggested that individuals held different goals and adopted different strategies during the disclosure process. Frost et al. (2006) refer to such goals of disclosure as being related to sources of personal validation of self. This personal validation is either self-directed (where emphasis is placed on self-evaluation) or other-directed (where the individual places more emphasis on external evaluation of others). Communication within the disclosure process is presented as either open (e.g. open to exchanges of information or feedback) or closed (e.g. adopting a guarded approach). The model proposes that the combination of personal validation goals and communication approaches produces four disclosure strategies, as illustrated in Table 1. 
Table 1: Disclosure Management Strategies (Frost, Daniels, and Hudson, 2006)

<insert table 1 here>

The Disclosure Management Model (Frost et al., 2006) proposes that an individual whose goals of personal validation are self-directed, and who adopts an open strategy to communication, could be classed as having an exploratory disclosure strategy. The second strategy, characterised by self-directed personal validation is that of the oppositional style. This strategy is markedly different from the exploratory style in that it is characterised by a closed approach to communication. Individuals adopting the placatory style view disclosure as an exercise of external evaluation and therefore their goals relate to the gaining of approval of others and the securing of emotional support. The focus on gaining approval sets the placatory style apart from the evasive strategy, in which the focus is on the avoidance of emotional harm.

The implementation of the Disclosure Management Model (Frost et al., 2006) has a number of practical implications to both treatment providers and clients. Identification of disclosure strategies at the beginning of treatment might enable interventions to be more effective. Frost et al. (2006) suggest that this would be achieved through the avoidance of "time-consuming and profitless confrontation" with individuals who possess oppositional and evasive management strategies. Given existing research into the importance of client engagement on treatment effectiveness (DiClemente, Bellino, and Neavins, 1999), the exploratory style should be most closely associated with treatment effectiveness and oppositional the least effective. 
The model is not however without its limitations. The qualitative methodology used (grounded theory approach), small sample size, and focus on sexual offenders calls into question the generalisability of the model.

Implementation of the Disclosure Management Model requires a method of assessing disclosure styles that is reliable. There does not appear to be an existing self-report measure to assess disclosure styles, as defined by Frost et al. (2006). Whilst self-report is not without its limitations, it is nonetheless a helpful starting point in developing the area. Development of an assessment tool will also allow for the exploration of associated factors that may impact on a client's disclosure strategy, for example that of personality.

\section{Personality Traits and Disclosure}

Previous research in the field of social psychology has focused on the influence of personality on the process of disclosure (e.g. Journard, 1958). This is not surprising given that personality can be defined as an organised set of characteristics possessed by a person that influences their cognitions, motivations, and behaviour (Ryckman, 2004). Early research exploring the relationship between personality and self-disclosure (e.g. Archer, 1979) however provided little consistency in identifying personality variables associated with self-disclosure (Pedersen and Breglio, 1968). In addition, existing research is limited to explaining disclosure occurring within interactions that do not reflect the environment in which disclosure is expected to take place in forensic settings. For example, Ross (2008) highlights that offender cultures can be "predatory, brittle and dangerous environments where self-disclosure can lead to death at worst and low 
social status and routine predation by others at best" (p.59). Research is therefore needed to explore the impact of personality on disclosure strategies adopted in forensic clients.

A predominant model of personality that has been used to explore personality correlates is the five-factor model (Costa and McCrae, 1992). The theory proposes that there are five traits of personality - Neuroticism, Extraversion, Openness to experience (hereafter Openness), Agreeableness, and Conscientiousness. As a result of exploration of the literature, it appears that descriptions of the five personality traits have similarities to the strategies of disclosure presented by Frost et al. (2006). For example, the exploratory disclosure style, characterised by openness to exchanges of information has similarities to the concept of Openness (as described by the adjectives as curious, insightful). Furthermore, individuals displaying an evasive disclosure style possess a fear of negative evaluations from others, which has similarities to the concept of Neuroticism (as described by the adjectives as anxious, worrying, self-pitying and tense). Exploring potential similarities and relationships between disclosure and personality may facilitate understanding of the nature and development of disclosure strategies adopted in forensic clients.

The exploration of potential associations between personality and disclosure will also allow for other personality correlates that may impact on the disclosure process to be identified. For example, Robins, Tracy and Trzesniewski (2001) explored the relationship between the Openness and trait self-esteem (an individual's overall positive evaluation of the self: Rossenberg, 1990). Robins et al. (2001) reported that Openness correlated positively with high 
self-esteem. It could therefore be the case that personality factors, specifically Openness, and self-esteem are associated with the exploratory disclosure strategy. Exploration of the impact that self-esteem has on disclosure has additional value as the Disclosure Management Model (Frost et al., 2006) postulates that the disclosure strategy adopted is mediated by the individual's goal of disclosure in relation to their personal validation of self. If self-esteem is found to predict exploratory disclosure, increasing self-esteem prior to engagement in therapy may serve to improve treatment effectiveness.

The aim of the current research was to develop a self-report measure that could be used to assess disclosure styles in a sample of adult male offenders convicted of violent (non-sexual) and acquisitive offences. The current research also attempted to explore relationships between personality, self-esteem and disclosure. As a result, a number of specific hypotheses were made:

Hypothesis 1 - Participants would report behaviours present during the disclosure process consistent with the four disclosure strategies reported by Frost et al. (2006).

Hypothesis 2 - Participants scoring higher on the Openness personality factor will demonstrate more behaviours associated with the Exploratory disclosure strategy.

Hypothesis 3 - Participants scoring higher on the Neuroticism factor would present with more behaviours associated with the Evasive disclosure strategy.

Hypothesis 4 - Individuals with higher self-esteem will score higher on the Openness personality factor and as a result will demonstrate more behaviours associated with Exploratory disclosure style. 
Hypothesis 5 - Post-treatment offenders would display more behaviours characteristic of the Exploratory disclosure strategy as compared to pre-treatment offenders.

\section{Part 1 - Development of the Disclosure Management Questionnaire (DMQ)}

\section{Method}

\section{Participants}

15 Forensic Psychologists (including Chartered Psychologists and Forensic Psychologists in Training with at least 12 months experience) from one geographical area of Her Majesty's Prison Service were invited to participate in the development of questionnaire items. Responses were received from 11.

\section{Procedure}

Participants were provided with a short description of the four disclosure strategies as reported by Frost et al. (2006), these descriptions are provided below in Table 2 .

Table 2: Descriptions of disclosure strategies provided to the forensic professional group

$<$ Insert Table 2 here $>$ 
Using the descriptions presented in Table 2, the sample were asked to draw on their experience in order to report the three most likely presentations they felt an offender with each disclosure style would display. All responses were provided anonymously. The contributions provided were added to descriptions proposed by Frost et al. (2006).

In order to gain an independent assessment of the behaviours that were descriptive of each disclosure strategy, a modified version of the Delphi technique was utilised. The Delphi technique has been found to be an efficient way to combine the knowledge and abilities of a group of experts (Lindeman, 1975). Invites were sent out to 11 Forensic Psychologists to assist in the assessment. Two experienced Forensic Psychologists responded, both of whom had over 5 years of experience of working with forensic clients in secure settings. The two raters were instructed to independently sort an initial 54 items (as initially generated by the forensic sample and the research of Frost et al. 2006), into the four disclosure strategies. Following this process, amendments to the wording of items were made and five items were omitted. The process was then repeated, following which analysis revealed an excellent level of agreement was achieved as measured by Cohen's Kappa of above .75 . This process resulted in the generation of 49 questionnaire items.

Part 2: Factor Structure of the DMQ and Relationships between DMQ Subscales, Personality and Self Esteem

\section{Method}




\section{Participants}

Adult male prisoners residing in one category $B$ prison establishment ${ }^{1}$ were used to explore the factor structure of the 49-item questionnaire and to identify items for possible deletion. The sample consisted of 94 participants, all of which were serving a custodial sentence for an offence they had been convicted for. The majority of the sample ( $N=35,47.8 \%)$ were between the ages of 25 to 36 years and described themselves of 'White' ethnic origin $(81.9 \%, \mathrm{~N}=82)$, with the remainder of the sample describing themselves of 'Black' ( $N=4,4.3 \%)$, 'Asian' ( $N=2$, $2.2 \%)$, and 'Other' ethnic origin ( $N=4,4.3 \%)$.

\section{Procedure}

Questionnaire packs were distributed which included a research information sheet, demographic questions, measures as described below and a question aimed to assess the treatment interventions they had recently engaged in. Respondents were advised via the information sheet of issues relating to the provision and withdrawal of consent.

\section{Measures}

\section{Disclosure Strategy Questionnaire}

Participants rated the extent they agreed with 49 statements using a 5 point Likert scale $(1=$ strongly disagree and 5 = strongly agree). Examples included "I try to promote positive feedback about myself" and "I do not seek out feedback".

\footnotetext{
${ }^{1}$ Category B prisons hold adult male prisoners (over 21 years of age) who are a risk to the public but do not need the highest level of security and the aim is to make escape very difficult
} 
International Personality Item Pool Inventory (IPIP) (Goldberg, 1999)

Participants indicated how accurately each of the 50 items describes them using a 5 point Likert scale $(1=$ very inaccurate and $5=$ very accurate). Five personality traits are assessed: Extraversion, Agreeableness, Conscientiousness, Neuroticism and Openness. The 50 item IPIP has been found to have good internal reliability $(.86, .76, .85, .86$, and .78 for Extraversion, Agreeableness, Conscientiousness, Neuroticism, and Openness, respectively; Socha, Cooper and McCord, 2010).

Texas Social Behaviour Inventory (TSBI) (Helmrich and Stapp, 1974).

The Inventory consists of 16 items on a 5 point Likert scale $(1=$ not at all like me and $5=$ very much like me), to assess self-esteem in respondents. Of the 16 items, 6 are reversed to produce a mean score for each participant. The TSBI has been found to have good internal reliability (alpha coefficient .81, Helmrich and Stapp, 1974).

\section{Results}

\section{Data Screening}

A total of 89 values (out of a potential 10,810) were missing from the data set. Analysis revealed that data was missing at random (Chi Square $=2205.330$, DF $=2663, p=1.00$ ), and therefore it was replaced with group means in accordance with procedure recommended by Tabachnick and Fidell (2007). Univariate outliers were identified and transformed. No multivariate outliers were identified in the data. 


\section{Factorability of the Data}

Analysis revealed the Kaiser-Meyer-Olkin value to be .649, therefore exceeding the recommended value of .6 (Tabacknick and Fidell, 2007) and Bartlett's Test of Sphericity reached significance $($ Chi Square $=2630.785, d f=1176, p=0.000 p<.5$ ), supporting the factorability of the data.

Responses were subjected to Exploratory Factor Analysis (EFA) using Principle Component Analysis. The initial analysis produced 14 factors with eigenvalues greater than 1.0 (accounting for a cumulative $72.2 \%$ of variance). Parallel Analysis (Horn, 1965) indicated that a four factor structure should be adopted. To aid the interpretation of a four-factor solution, EFA with direct oblim rotation was performed ${ }^{2}$. The four-component solution explained a total of $41.7 \%$ of variance. To aid interpretation of the solution, only factor loadings of above .32 (accounting for $10 \%$ of overlapping variance) were considered (Comrey and Lee, 1992). Items that did not load on any one factor (below .32) or showed loadings of above .32 on more than one factor were removed and analysis was undertaken until a simple factor solution was achieved. The revised four-factor solution explained a total of $42.79 \%$ of variance and is illustrated in Table 3.

Table 3: Factor Loadings of the 33 Disclosure Management Questionnaire items

\section{<Insert Table 3 here}

\footnotetext{
${ }^{2}$ The Direct Oblimin technique was adopted as correlations were expected across factors.
} 


\section{Factor Structure}

Factor 1 was labelled Exploratory Engagement as items reflected an open or closed approach to engagement and the exploration of insight. Items loading on factor 2 (labelled Placatory/Evasive Engagement) reflected presentations consistent with the appeasement and avoidance of the disclosure process. Factor 3, labelled as Passive Resistance reflected resistance to the disclosure process, albeit using strategies that were not explicit. Finally, items loading on factor 4 (labelled Active Resistance) reflected the active resistance of disclosure. The analysis therefore resulted a 33 item Disclosure Management Questionnaire (DMQ) consisting of four sub-scales; Exploratory Engagement, Placatory/Evasive Engagement, Passive Resistance and Active Resistance. Following the reversal of items (items 6, 8, 12 and 32); higher scores on each subscale reflect the presentation of the individual being more consistent with the theme of the subscale.

A preliminary analysis was undertaken on the DMQ to test assumptions of normality, linearity and homoscedasticity. As the total scores on all four subscales were non-normally distributed, non-parametric tests were utilised for the subsequent analysis ${ }^{3}$.

Relationship between Disclosure Management Questionnaire Subscales, Personality Factors and Self-Esteem

\footnotetext{
${ }^{3}$ Non-Parametric tests were utilised as the assumption of normal distribution on which parametric tests are based were not met by the data collected in the current study.
} 
To assess the relationship between the DMQ subscales, personality factors and self-esteem, Spearman's rho was utilised. Correlation coefficients were explored for relationships between subscale total scores. These are displayed in Table 4.

Table 4: Spearman's Rank Order Correlation Coefficients ( $\rho$ ) of DMQ subscales, Personality Factors and Self-esteem ( $N=94)$

\section{<Insert Table 4>}

A significant positive correlation between Placatory/Evasive Engagement and Neuroticism was identified (Hypothesis 3), in that higher scores of Neuroticism were associated with more placatory and evasive presentations. Significant positive correlations were identified between the Passive Resistance subscale and all five personality factors; in that individuals who scored highly on the Passive Resistance subscale reported higher scores of Agreeableness, Extraversion, Conscientiousness, Neuroticism and Openness. A significant positive correlation between the subscale of Active Resistance and Neuroticism was also identified, in that higher scores of Neuroticism were associated with more active resistance of the disclosure process. Exploratory Engagement did not correlate significantly with any of the five personality factors (Hypothesis 2).

No relationship was found between the personality factor of Openness and self-esteem

(Hypothesis 4). The construct of self-esteem did however demonstrate a significant positive 
correlation with the Exploratory Engagement subscale, in that higher ratings of self-esteem were associated with increased scores on the Exploratory Engagement subscale. Analysis also revealed a significant negative correlation between self-esteem and Active Resistance in that higher scores on the Active Resistance subscale were associated with low self-esteem.

\section{Comparison of disclosure strategies in pre-treatment and post treatment groups}

Analysis also sought to explore whether individuals that had engaged in therapy presented as more exploratory in their disclosure style following treatment (Hypothesis 5). A Mann-Whitney $\mathrm{U}$ Test revealed a significant difference in Exploratory Engagement scores of the pre-treatment group ( $M d=59.27, n=57)$ and the post treatment group $(M d=61, n=37), U=815, z=-1.86, p$ $=.03, r=.019$, in that individuals who had previously engaged in treatment reported as possessing higher levels of exploratory engagement.

\section{$\underline{\text { Discussion }}$}

The current research resulted in the development of a 33 item self-report measure of disclosure: the Disclosure Management Questionnaire (DMQ). Subsequently, the development of the DMQ allowed for relationships between personality variables and disclosure strategies to be explored. Analysis revealed a number of significant and interesting relationships between disclosure, personality traits and trait self-esteem.

The DMQ assesses four disclosure strategies through the inclusion of four subscales within the measure. The Exploratory Engagement subscale is characterised by a genuine openness to 
exchanges of information and feedback and therefore fits with the exploratory disclosure strategy proposed by Frost et al. (2006). The Placatory/Evasive Engagement subscale contains items that are indicative of behaviour that both appeases and avoids the disclosure process. Items included in the subscale therefore fit with both the placatory style and evasive strategy proposed by Frost et al. (2006). The Active Resistance subscale is indicative of individuals who are openly resistant to the disclosure process, therefore translating theoretically with the Oppositional strategy proposed by Frost et al. (2006). The Passive Resistance subscale of the DMQ contains items indicative of individuals who are resistant to the disclosure process but whom do not communicate this openly. Whilst there are some similarities between this subscale and the 'evasive' and 'oppositional' strategies, the subscale failed to reflect active avoidance of disclosure. It should also be noted that the DMQ provides a profile of scores across all four subscales. Whilst clients may present with a preferred strategy, they are likely to adopt behaviours that are consistent with all four subscales.

There are a number of potential reasons which may explain why the DMQ did not map directly onto the four disclosure styles proposed by Frost et al. (2006). Firstly, Frost et al. (2006) utilised a sample of sexual offenders to develop their model. The current study explored disclosure strategies of violent (non-sexual) and acquisitive offenders. It may be the case that significant differences are present within these two offender populations that account for differences in presentations during the disclosure process. For example, sexual offenders have been found to be more sensitive to rejection as compared to other types of offenders (Ward, McCormack and Hudson, 1997), therefore potentially making such a group more concerned about evaluation from others (adopting an other-directed source of personal validation). In addition, differences 
in the prevalence of Antisocial Personality Disorder (APD) have been noted across sexual and non-sexual populations (National Offender Management Service, 2011) which could potentially explain the differences presented across the two samples. Secondly, the Disclosure Management Model (Frost et al., 2006) was developed from a sample of 16 offenders. It may therefore be that the model is unable to be replicated directly and further exploration is needed using larger and more diverse samples.

Analysis revealed a number of significant and interesting relationships between personality traits and disclosure as measured using the DMQ. The prediction was made that as a result of descriptions of the personality factor of Openness (curious, insightful: John, 1989a), individuals who score highly on this construct would present with behaviours consistent with the Exploratory disclosure strategy. The current study did not support this hypothesis. On revisiting the literature, it appears that McCrae and Costa (2003) highlight that their conceptualisation of Openness should not be confused with the concept of self-disclosure. Instead, they highlight that Openness refers to one's "receptiveness to new ideas, approaches, and experiences" (McCrae and Costa, 1997a, p. 46). The definition of Openness provided by Costa and McCrae (2003) would therefore explain the reasoning for the above finding.

It was hypothesised that individuals scoring highly on the construct of Neuroticism would present with behaviours consistent with the Evasive disclosure strategy. As the DMQ collapsed the Placatory and Evasive Strategies proposed by Frost et al. (2006) into one management style termed Placatory/Evasive Engagement, analysis was undertaken to assess this subscale and 
Neuroticism. Analysis revealed that higher scores of Neuroticism were associated with more placatory and evasive presentations during the disclosure process. One possible explanation for this finding draws on the research of Clark, Wilson and Mineka (1994), in which it was argued that individuals with high levels of Neuroticism are sensitive to negative stimuli, such as disclosure. Furthermore, Lommen, Engelhard and van den Hout (2010) proposed that as a result of such sensitivity, individuals' use a "better safe than sorry" strategy, in which potentially negative stimuli is avoided. Therefore the Placatory/ Evasive Engagement could serve the function of assisting the client in avoiding potential negative evaluations from others, either as a result of the self-monitoring of information or through overt avoidance. A relationship was also found between the subscale of Active Resistance and Neuroticism, in that higher scores of Neuroticism were associated with more active resistance of the disclosure process. The "better safe than sorry" strategy (Lommen et al., 2010) could also provide some explanation for this finding.

Due to the lack of previous research, the study also adopted an exploratory approach to the relationship of personality and disclosure. Analysis revealed relationships between the Passive Resistance subscale and all five personality factors. Whilst it therefore appears that all five personality traits impact upon the adoption of the Passive Resistance strategy, the correlational methodology used limits the ability to comment on the casual nature of this relationship. Further analysis would benefit from adopting a causal model approach in order to assist in explaining this finding. In addition, future exploration would benefit from drawing on existing knowledge of the association between the five factor personality traits and extreme forms of 
personality, such as personality disorder. Again, this will allow for improved understanding about the causal nature of disclosure and assist in the identification of potential difficulties that may arise during the disclosure process.

Previous research has highlighted the link between the Openness personality factor and the personality construct of self-esteem (Robins, Tracy and Trzesniewski, 2001). Exploration in the current study did not identify a significant relationship between the two constructs. Significant relationships were, however, identified directly between self-esteem and disclosure. High selfesteem was associated with increased Exploratory Engagement, whereas low self-esteem was associated with increased Active Resistance. Whilst the current study is unable to comment on the causal nature of this relationship, it appears that an individual's self-esteem is an important factor within the disclosure process of forensic clients. It would be useful for future research to explore whether client's self-esteem influences exploratory disclosure, or whether exploratory engagement in therapy promotes high self-esteem.

The initiation of the development of the DMQ and subsequent understanding of related personality factors has a number of potential benefits to the clinician, the client and future areas of research. In recent decades there has been considerable development in the field of offender rehabilitation following the emergence of meta-analytic studies detailing "what works" in reducing re-offending (e.g. Andrews, Zinger, Hoge, Bonta, Gendreau and Cullen 1990). Effective interventions have been found to match the offender's actuarial risk level, target criminogenic need and be responsive to the individual characteristics of the offender 
(Andrews, Bonta and Hoge 1990). Specific responsivity refers to more individual factors such as the forensic client's readiness to engage in the change process. Given that willingness to disclose information about one's offending behaviour is argued as a critical factor within motivation to engage (Frost, Ware and Douglas, 2009), awareness of an individual's disclosure strategy can assist understanding about client engagement and the function this serves. Development of such understanding will therefore allow clinicians to be more responsive to individual offenders.

The DMQ also has the potential to be developed into a collaborative assessment tool. Whilst acknowledging the limitations of self-report and social desirability effects, engaging clients in discussion around the items of the DMQ may be beneficial for a number of reasons. Firstly, the process may encourage the client to reflect on their strategies used and assist in developing insight into the function these serve. Secondly, discussion will facilitate the identification of barriers to open and exploratory engagement. Such barriers (for example, those arising from the client's underlying beliefs about themselves) can therefore be explored prior to, or during, the intervention. Exploration can also be undertaken with the client as to factors that may increase the likelihood of exploratory engagement. Finally, engaging in a collaborative process will facilitate open discussions with the client about disclosure throughout the duration of the intervention. This may assist the therapeutic alliance between client and clinician, which has been documented to account for approximately $20 \%$ of variance in treatment effectiveness (Martin, Garske and Davis, 2000). 
In addition to practical implications, the initiation of the DMQ can assist in future research in the field of client engagement and disclosure. The measure can be used to further explore the function of disclosure, and factors that are associated with each strategy. For example, given that behaviour changes over time, it would be useful to explore the stability of an individual's disclosure style. If changes occur, attention should be paid to the function this serves and factors that act as catalysts to change. The current study reported that clients who had engaged in a treatment intervention had significantly higher scores on the Exploratory Engagement subscale than individuals who had not engaged in therapy. This finding suggests that engagement in treatment itself may serve to improve exploratory disclosure. It would be beneficial to explore the characteristics of interventions that maximise such change in how a client presents during the disclosure process.

The development of the Disclosure Management Questionnaire was based on responses from 94 respondents, all of which were serving a custodial sentence for a non-sexual offence. It is therefore recognised that the generalisability of the current research is limited to such populations and is not representative of the prison population as a whole. It is therefore necessary for this research to be replicated with larger and more diverse samples. This will also allow for the reliability and validity of the DMQ to be further assessed and increase the potential for parametric tests to be utilised in order to strengthen future findings. As discussed, implementation of a disclosure management model requires a simple, reliable method of assessing disclosure strategies amongst individuals engaging in therapy. Whilst the researcher 
recognises potential limitations of the current study, it is proposed that the DMQ provides the first step in the process of developing such a measure.

\section{Conclusions}

Willingness to disclose information about oneself and one's offending behaviour is argued as a critical factor in the process of engagement (Frost, Ware and Douglas, 2009) and potentially effectiveness of treatment. The DMQ developed in the current research has valuable practical implications relating to the development of understanding of disclosure strategies and the functions these serve. Future validation and development of the measure is therefore recommended. This will allow the DMQ to be reliably implemented and the relationships between disclosure, personality and self-esteem to be explored further.

\section{Implications for practice}

- Willingness to disclose information about one's offending behaviour is argued as a critical factor within motivation to engage (Frost, Ware and Douglas, 2009). The development of the Disclosure Management Questionnaire as a method of assessing an individual's disclosure strategy can assist understanding about client engagement and the function this serves. Development of such understanding will therefore allow clinicians to be more responsive to individual offenders, potentially increasing the effectiveness of interventions aimed at reducing reoffending.

- Development of an assessment tool will also facilitate the exploration of associated factors that may impact on a client's disclosure strategy, for example that of personality.

- The Disclosure Management Questionnaire also has the potential to be developed into a collaborative assessment tool which could be used to encourage clients to reflect on the strategies of disclosure they adopt. The Disclosure Management Questionnaire can also be used to facilitate the identification of barriers to open and exploratory engagement. 


\section{References}

Andrews, D.A., Bonta, J., \& Hoge, R. D. (1990). Classification for effective rehabilitation: Rediscovering psychology. Criminal Justice and behavior, 17, 19-52.

Andrews, D.A., Zinger, I., Hoge, R. D., Bonta, J., Gendreau, P., \& Cullen, F. T. (1990). Does correctional treatment work? A clinically relevant and psychologically informed Meta-Analysis. Criminology, 28, No. 3 pp369.

Archer, R.L. (1979). The role of personality and the social situation. In G.J. Chelune (Ed), Selfdisclosure (pp. 1-27). San Franscisco: Jossey-Bass.

Bartlett, M. S. (1954). A note on the multiplying factors for various chi square approximations. Journal of the Royal Statistical Society, 16 (Series B), 296-8.

Clark, L. A., Wilson, D. \& Mineka, S. (1994). Temperament, Personality, and the Mood and Anxiety Disorders. Journal of Abnormal Psychology, 103 (1), pp. 109-116.

Comrey, A. L., \& Lee, H. B. (1992). A first course in factor analysis (2 ${ }^{\text {nd }}$ ed.). Hillsdale, NJ: Erlbaum. 
Costa, P. T., \& McCrae, R. R. (1992). Revised NEO personality inventory (NEO PI-R) and NEO-FiveFactor Inventory (NEO-FFI) professional manual. Odessa, FL: Psychological Assessment Resources.

DiClemente, C., Bellino, L. \& Neavins, T. (1999). Motivation for change and alcoholism treatment. Alcohol Research \& Health, 23(2) pp. 86-92.

Dindia, K., Fitzpatrick, M. A., \& Kenny, D. A. (1997) Self Disclosure in spouse and stranger interaction: A social relations analysis. Human Communication Research, 23, 388-412 citied in Endler et al. (2002) European Journal of Personality, 16, 239-269.

Frost, F., Daniels, K., \& Hudson, S. M. (2006). Disclosure strategies among sex offenders: A model for understanding the engagement process in groupwork. Journal of Sexual Aggression, Vol. 12, No. 3, pp. 227-244.

Frost, A., Ware, J., \& Boer, D. (2009). An integrated groupwork methodology for working with sex offenders. Journal of Sexual Aggression, Volume 15, Number 1, March 2009 , pp. 21-38.

Goldberg, L. R. (1999). A broad-bandwidth, public-domain, personality inventory measuring the lower-level facets of several five-factor models. In I. Mervielde, I. Deary, F. DeFruyt, \& F. Ostendorf (Eds.), Personality psychology in Europe (Vol. 7, pp. 7-28). Tilburg, The Netherlands: Tilburg University Press. 
Helmrich, R., \& Stapp, J. (1974). Short form of the Texas Social Behavior Inventory: An objective measure of self-esteem. Bulletin of the Psychonomic Society, 4, 473-475.

Horn, J. L. (1965). A rationale and test for the number of factors in factor analysis. Psychometrika, 30, 179-185.

John, O. P. (1989a). Towards a taxonomy of personality descriptors. In D. M. Buss \& N. Cantor (Eds). Personality psychology: Recent trends and emerging directions (pp. 261-271). New York: Springer-Verlag.

Journard, S. M. (1958). A study of self-disclosure. Scientific American, 198(5), 77-82.

Lindeman, C. (1975) Delphi survey of priorities in clinical nursing research. Nursing Research 24, 434-441.

Lommen, M. J. J., Engelhard, I. M., Sijbrandij, E. M. \& Van den Hout, M.A. (2010). Do individual differences in fear conditioning before trauma predict later posttraumatic stress? Presented at VGCT: Veldhoven. 
Martin, D. J., Garske, J. P. \& Davis, M. K. (2000). Relation of the therapeutic alliance with outcome and other variables: a meta-analytic review. Journal of Consulting \& Clinical Psychology, 68, pp. 438-50.

McCrae, R. R. \& Costa, P. T. (2003). Personality in Adulthood. A Five Factor Theory Perspective. The Guildford Press.

McCrae, R.R., \& Costa, P.T. (1997) Personality trait structure as a human universal. American Psychologist, 52, 509-516.

National Offender Management Service. (2011). Working with Personality Disordered Offenders

Pallant, J. (2010). SPSS Survival Manual (4 ${ }^{\text {th }}$ ed.). Open University Press.

Pedersen, D., \& Breglio, V. (1968). Personality correlates of actual self-disclosure. Psychological Reports, 22, 495-501.

Ross, E. C. (2008). Investigating the Relationship Between the Therapeutic Alliance and Treatment Outcome in Violent Offender Treatment. A thesis submitted to the Victoria University of Wellington in fulfillment of the requirements for the degree of Doctor of Philosophy in Psychology. 
Robins, R.W., Tracy, J. L., \& Trzesniewski, K. (2001). Personality Correlates of Self Esteem. Journal of Research in Personality, 35, 463 -482.

Ryckman, R. (2004). Theories of Personality. Belmont, CA: Thomson/Wadsworth.

Socha, A., Cooper, C. A., \& McCord, D. M. (2010). Confirmatory factor analysis of the M5-50: An implementation of the International Personality Item Pool item set. Psychological Assessment, $22(1), 43-49$.

Strauss, A. \& Corbin, J. (1990). Basics of qualitative research: Grounded theory procedures and techniques. Sage Publications.

Tabachnick, B. G., \& Fidell, L. S. (2007). Using Multivariate Statistic, 5th ed. Boston: Allyn \& Bacon 
Table 1: Disclosure Management Strategies (Frost, Daniels, \& Hudson, 2006)

\begin{tabular}{|c|c|c|}
\hline & Communication Style & \\
\hline $\begin{array}{l}\text { Personal } \\
\text { Validation of } \\
\text { self }\end{array}$ & Open & Closed \\
\hline Self-directed & $\begin{array}{l}\text { Exploratory } \\
\text { Open to exchanges of information } \\
\text { Reflective towards feedback } \\
\text { Develop insight through } \\
\text { collaborative working }\end{array}$ & $\begin{array}{l}\text { Oppositional } \\
\text { View disclosure process with suspicion } \\
\text { View therapy as a form of manipulation } \\
\text { Seek to maintain initial positions } \\
\text { Feedback is scrutinised for criticism }\end{array}$ \\
\hline $\begin{array}{l}\text { Other- } \\
\text { directed }\end{array}$ & $\begin{array}{l}\text { Placatory } \\
\text { Concerned with attracting } \\
\text { interpersonal support } \\
\text { Information provided is monitored } \\
\text { Elaboration is preferred over brevity }\end{array}$ & $\begin{array}{l}\text { Evasive } \\
\text { Avoid disclosure to minimise shame } \\
\text { Provide minimal amounts of information } \\
\text { Brevity is preferred technique } \\
\text { Engage in pre-session preparation }\end{array}$ \\
\hline
\end{tabular}


Table 2: Descriptions of disclosure strategies provided to the forensic professional group

An exploratory disclosure style is characteristic of someone who

- Adopts an open pro-active strategy to the exchange of information

- Has a reflective and considered attitude towards feedback

- Places more emphasis on their internal evaluation of themselves

- Deals with emerging issues with a discovery driven and pro-active stance in order to aid their understanding

An oppositional disclosure style is characteristic of someone who

- Adopts a close approach to communication

- Views invitations to engage in analysis of information with suspicion and even hostility

- Views the process of engaging in treatment as a controlling technique

- Seeks to promote and rigidly maintain initial positions and predispositions

- Scrutinises feedback for criticism

- Views success in their perceived ability to 'score points' against the clinician

An evasive disclosure style is characteristic of someone who

- Is fearful of negative evaluations

- Develops strategies to avoid disclosure

- Is drawn to the benefits of engaging in disclosure, coupled with fear of experiencing distress

- Perceives others involved in the disclosure encounter as threatening 
- Will provide minimal information required

- Uses impression management to disguise their distress / the real self

A placatory disclosure style is characteristic of someone who

- Aims to present themselves in a favourable light to others

- Often presents as compliant

- Focuses on meeting the expectations of others, at least in appearance

- Considers the disclosure process as an exercise in external evaluation

- Anticipates the process of disclosure as being interrogative

- Monitors information they provide to others in order to avoid rejection 
Table 3: Factor Loadings of the 33 Disclosure Management Questionnaire items

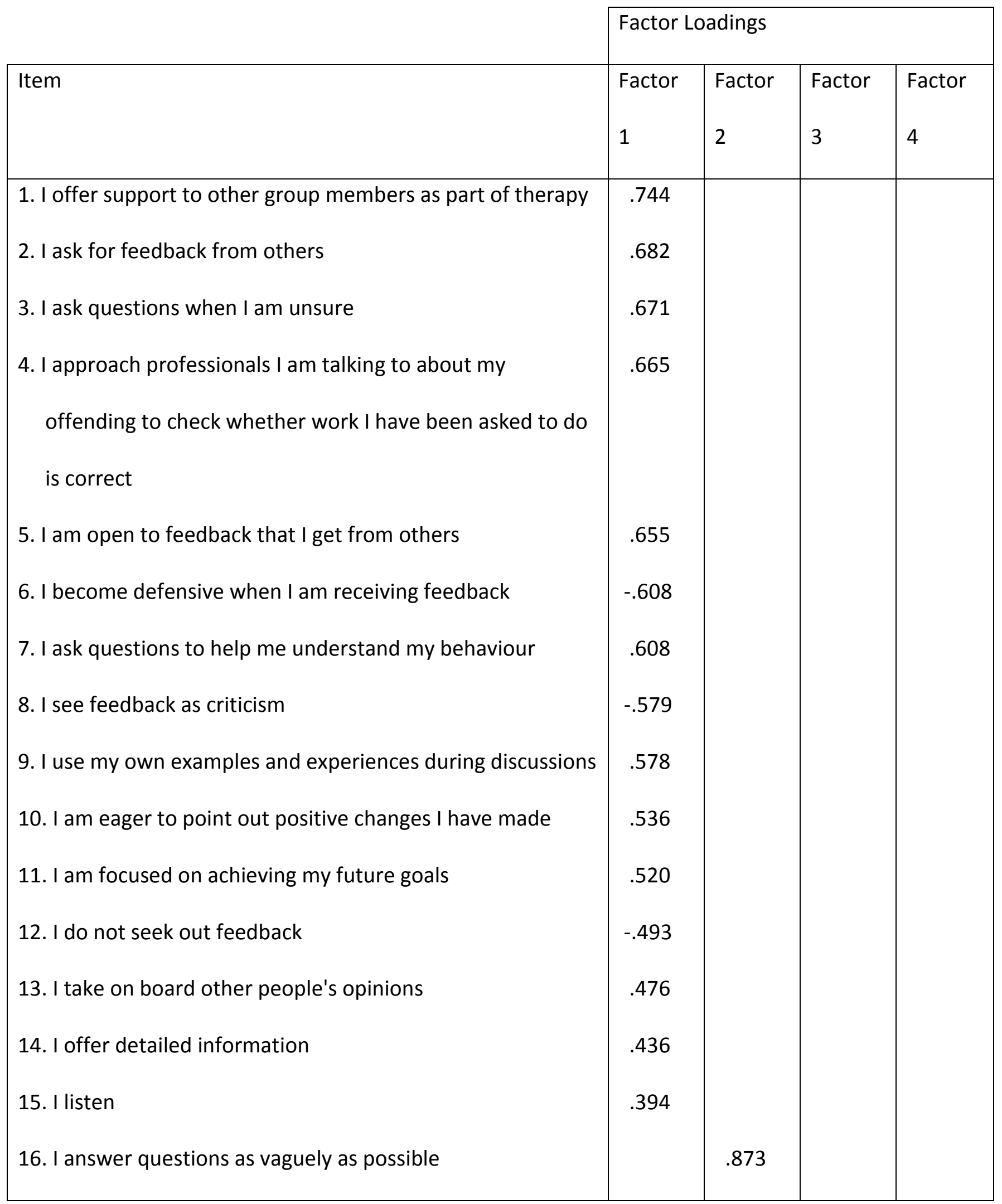




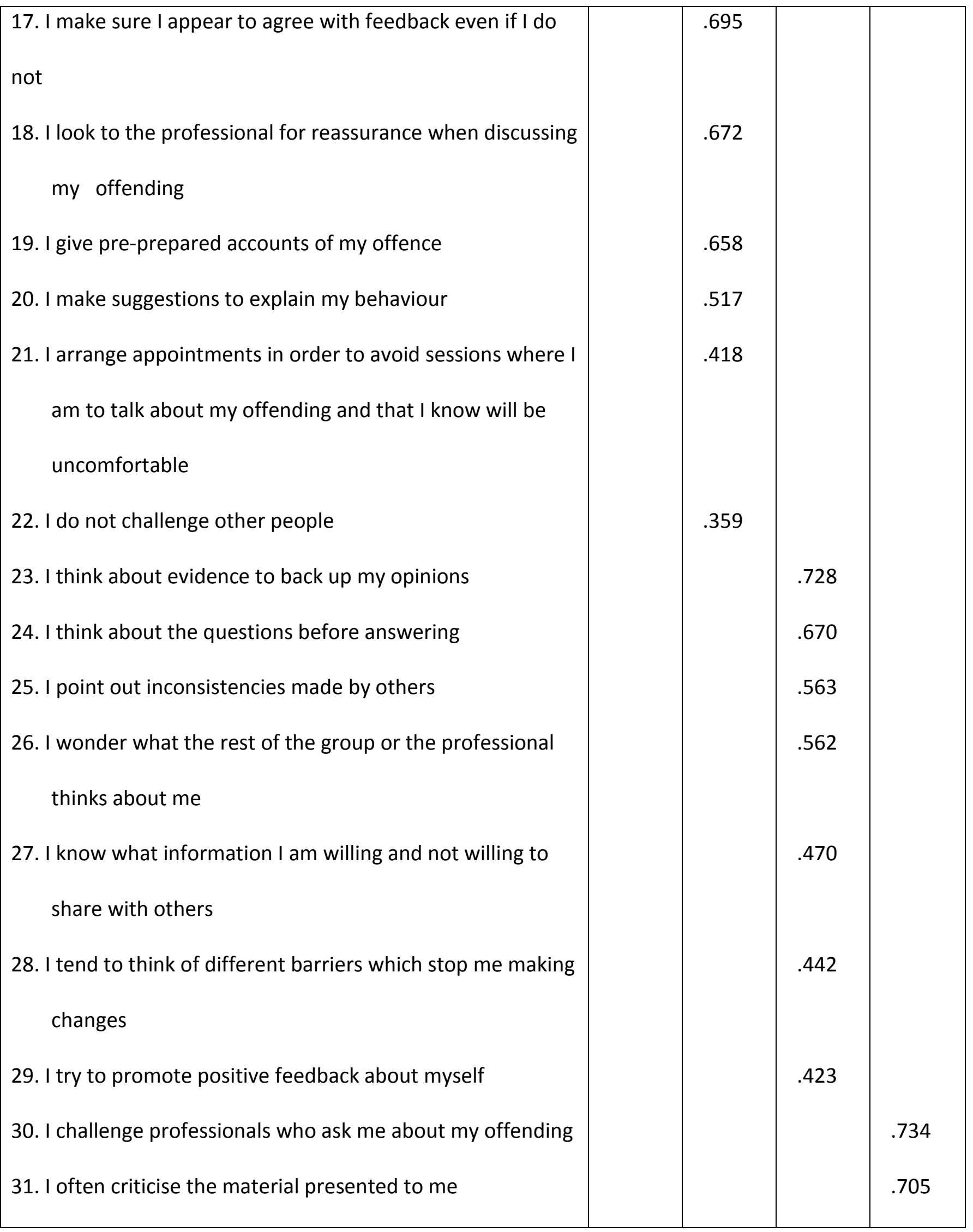




\begin{tabular}{|l|l|l|l|l|}
\hline $\begin{array}{l}\text { 32. I am prepared to deal with the concept of reducing my } \\
\text { risk of re-offending }\end{array}$ & & & & \\
$\begin{array}{l}\text { 33. I view the process of engaging in work around my } \\
\text { offending as an attempt to control me }\end{array}$ & & & & \\
\hline $\begin{array}{l}\text { Percentage of variance explained } \\
\text { Cronbach's Alpha }\end{array}$ & 19.74 & 9.50 & 7.81 & 5.74 \\
\hline
\end{tabular}

Note: Factor 1 = Exploratory Engagement, factor 2 = Placatory / Evasive Engagement, factor 3 =

Passive Resistance, factor 4 = Active Resistance 
Table 4: Spearman's Rank Order Correlation Coefficients ( $\rho)$ of DMQ subscales, Personality Factors and Self-esteem ( $\mathrm{N}=94)$

\begin{tabular}{|c|c|c|c|c|c|c|c|c|c|c|}
\hline & $\mathrm{EE}$ & PE & PR & AR & $A$ & $E$ & $C$ & $\mathrm{~N}$ & $\mathrm{O}$ & SE \\
\hline $\begin{array}{l}\text { Exploratory } \\
\text { Engagement }\end{array}$ & 1.0 & $-.27 * *$ & -.02 & $-.46 * *$ & .09 & .06 & .20 & -.15 & .01 & $.44^{* *}$ \\
\hline $\begin{array}{l}\text { Placatory/ } \\
\text { Evasive } \\
\text { Engagement }\end{array}$ & & 1.0 & .20 & $.31 * *$ & -.01 & -.12 & .10 & $.31 * *$ & .04 & -.15 \\
\hline $\begin{array}{l}\text { Passive } \\
\text { Resistance }\end{array}$ & & & 1.0 & .13 & $.23 *$ & $.29 * *$ & $.27^{* *}$ & $.29 * *$ & $.38 * *$ & .04 \\
\hline $\begin{array}{l}\text { Active } \\
\text { Resistance }\end{array}$ & & & & 1.0 & .06 & .01 & -.02 & $.24^{*}$ & .03 & $-.38 * *$ \\
\hline $\begin{array}{l}\text { Agreeable- } \\
\text { ness }\end{array}$ & & & & & 1.0 & $.36 * *$ & $.38 * *$ & $.29 * *$ & $.38 * *$ & $.31 * *$ \\
\hline Extraversion & & & & & & 1.0 & $.35 * *$ & .09 & $.23^{*}$ & .11 \\
\hline $\begin{array}{l}\text { Conscientiou } \\
\text {-sness }\end{array}$ & & & & & & & 1.0 & $.33^{* *}$ & $.35^{* *}$ & .17 \\
\hline Neuroticism & & & & & & & & 1.0 & $.39 * *$ & $-.30 * *$ \\
\hline Openness & & & & & & & & & 1.0 & .10 \\
\hline Self-Esteem & & & & & & & & & & 1.0 \\
\hline
\end{tabular}


${ }^{*} \mathrm{p}<.05 ;{ }^{*} \mathrm{p}<.01, \mathrm{EE}=$ Exploratory Engagement, $\mathrm{PE}=$ Placatory/Evasive Engagement, $\mathrm{PR}=$ Passive Resistance, $\mathrm{AR}=$ Active Resistance; $\mathrm{N}=$ Neuroticism, $\mathrm{E}=$ Extraversion, $\mathrm{O}=$ Openness, $\mathrm{A}=$ Agreeableness, $\mathrm{C}=$ Conscientiousness; SE = Self-esteem 